\title{
Lean blowout limits of a gas turbine combustor operated with aviation fuel and methane
}

\author{
Wei Xiao ${ }^{1}$ Yong Huang ${ }^{1}$
}

Received: 12 November 2014 / Accepted: 30 June 2015 / Published online: 9 July 2015

(C) The Author(s) 2015. This article is published with open access at Springerlink.com

\begin{abstract}
Lean blowout (LBO) limits is critical to the operational performance of combustion systems in propulsion and power generation. The swirl cup plays an important role in flame stability and has been widely used in aviation engines. Therefore, the effects of swirl cup geometry and flow dynamics on LBO limits are significant. An experiment was conducted for studying the lean blowout limits of a single dome rectangular model combustor with swirl cups. Three types of swirl cup (dual-axial swirl cup, axial-radial swirl cup, dualradial swirl cup) were employed in the experiment which was operated with aviation fuel (Jet A-1) and methane under the idle condition. Experimental results showed that, with using both Jet A-1 and methane, the LBO limits increase with the air flow of primary swirler for dual-radial swirl cup, while LBO limits decrease with the air flow of primary swirler for dual-axial swirl cup. In addition, LBO limits increase with the swirl intensity for three swirl cups. The experimental results also showed that the flow dynamics instead of atomization poses a significant influence on LBO limits. An improved semi-empirical correlation of experimental data was derived to predict the LBO limits for gas turbine combustors.
\end{abstract}

\section{List of symbols}

$\mathrm{A}_{1} \quad$ Area of primary swirler $\left(\mathrm{mm}^{2}\right)$

$\mathrm{A}_{2} \quad$ Area of secondary swirler $\left(\mathrm{mm}^{2}\right)$

Wei Xiao

csubeggar@163.com

Yong Huang

yhuang@buaa.edu.cn

1 Collaborative Innovation Center of Advanced Aero-Engine, National Key Laboratory of Science and Technology on Aero-engines, School of Energy and Power Engineering, Beihang University, Beijing 100191, People's Republic of China

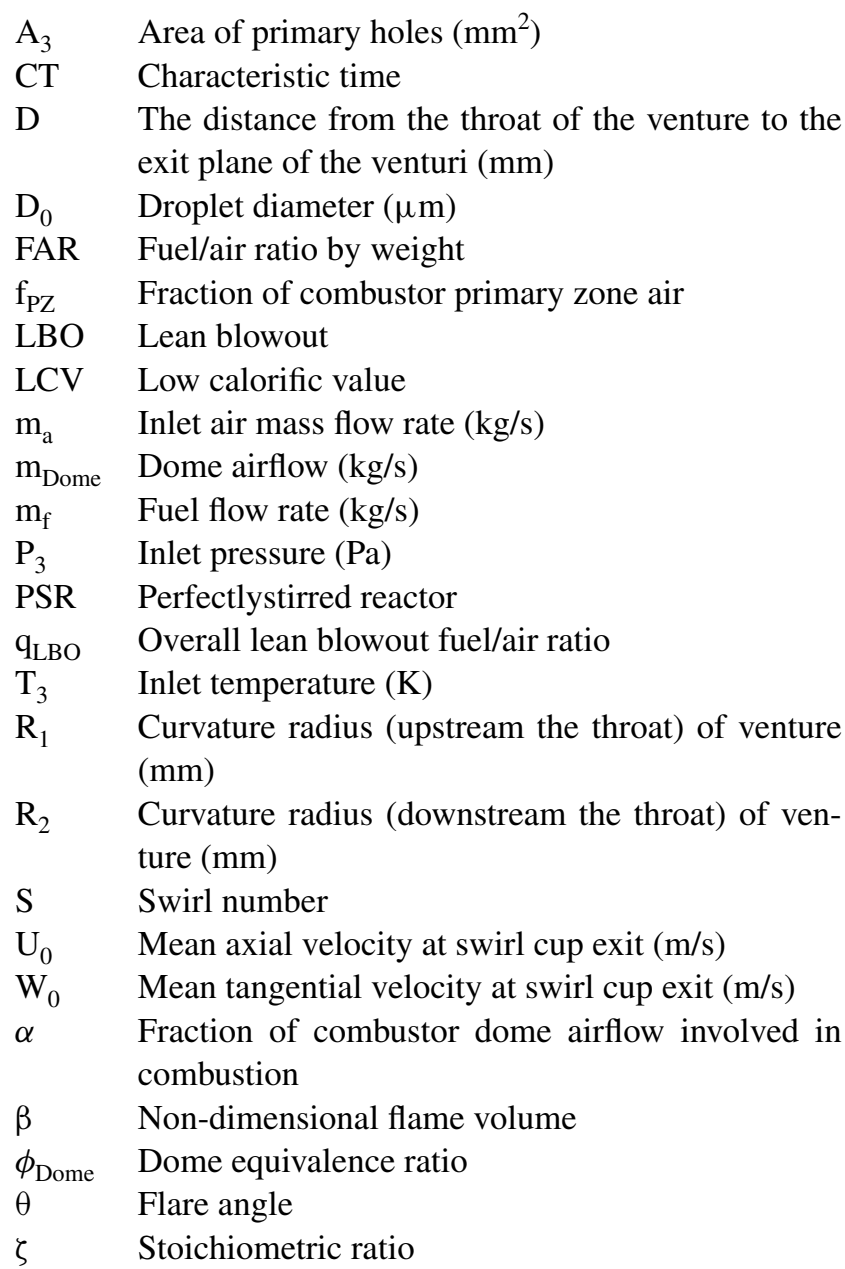

\section{Introduction}

Lean blowout (LBO) has been a big problem since the gas turbine was used as the propulsion system of aircraft 
Fig. 1 Schematic of single dome rectangular visualization Model combustor

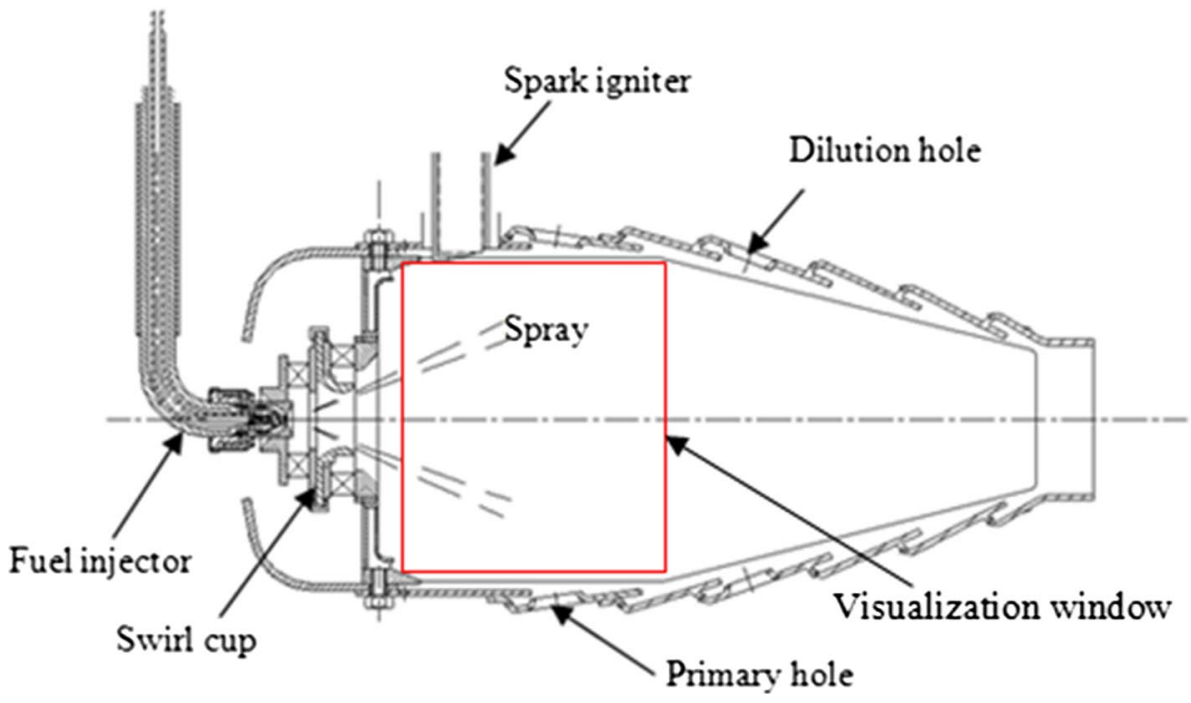

and power plant. Effects to improve power and propulsion systems have increasingly shifted to safety and stringent emission standards [1]. Lean premixed combustion including LDI (lean direct injection) [2] and LPP (lean premixed prevaporized) [3] is widely accepted as an option to achieve lower $\mathrm{NO}_{\mathrm{X}}$ emissions. However, the risk of flame blowout would increase as the fuel air ratio becomes lower. It would be also noted that LBO poses a significant safety hazard to aircraft engines as rapid power changes are always required. Thus, it is a challenge for engine designers to develop a combustor that achieves stable operation and low $\mathrm{NO}_{\mathrm{X}}$ emissions over the full range of engine conditions.

Swirl cup [4] has been widely used in engines to stabilize the flame by inducing a swirling flow of the reactants. As reviewed by Lefebvre [5], the majority of published work on LBO is for bluff-body flame holders and wellstirred reactors. The amount of experimental data published in the open literature for gas turbine combustor with swirl cup is much less extensive. Swirl cup geometries, including co-swirl, counter-swirl and vane angle, were studied to investigate its effects on LBO limits by Ateshkadi [6] and Durbin [7]. Sturgess [8] has studied the effect of primary zone air flow on LBO limits, and subsequently derived an empirical correlation to predict LBO limits. However, few investigations were focused on the effect of swirl cup flow dynamics on LBO limits.

The prediction tool for LBO limits of practical combustors is also a big issue in primary design stage. Lefebvre [9] developed a LBO model for heterogeneous fuel/ air mixtures based on the conception of well-stirred reactor (WSR). Another LBO model which is also named characteristic time (CT) model was developed by Plee and Mellor [10] for can-type combustors, and similar correlations were derived by Ozawa [11] and Discoll [12]. Hoffmann [13] used Peclet number based on the blow-off velocity of laminar flame speed to predict LBO limits of swirl flame. However, Mongia [14] pointed out that neither of the existing LBO correlation works with modern combustors and developed an iterative process based on Lindemann's formulation between LBO limits and combustion efficiency. Thus, many investigations focused on the improvement of existing correlations including Lefebvre's LBO correlation. Ateshkadi [15] improved Lefebvre's [6] LBO model by introducing a mixer hardware parameter. Xie [16] proposed a flame volume model developed from Lefebvre's model based on the concept of flame volume. Subsequently, $\mathrm{Hu}$ [17] used cold flow field to predict LBO limits based on FV model. However, the effect of swirl cup flow dynamics on LBO limits was ignored in these LBO model mentioned above.

The intent of this paper is to investigate the effect of swirl cup flow dynamics on lean stability behavior, with an aim of eventually modeling this behavior. Thus, three types of swirl cup with different sizes were employed in the experiment to study the lean stability. It was decided to approach the LBO problem in two distinct stages, initially with liquid fuel (Jet A-1), and last with gaseous fuel (methane). By this means the effects of liquid fuel atomization and spray evaporation can be separated from the flow dynamics effects. The effects of swirl cup flow dynamics were introduced in the improved LBO model developed from Lefebvre's [6] LBO model.

\section{Experimental methodology}

The schematic of the single dome rectangular model combustor used in this study is derived from 1/18 of an annular combustor [18]. The purpose of this gas turbine combustor is to provide experimental data of LBO limits for several 

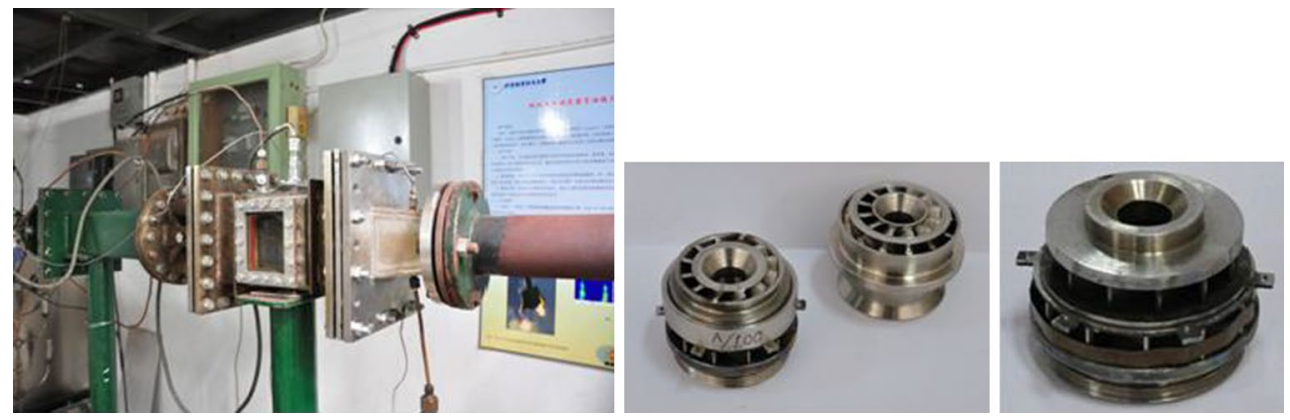

Fig. 2 Lean blow-out test rig and dual-axial/axial-radial/dual-radial swirl cups

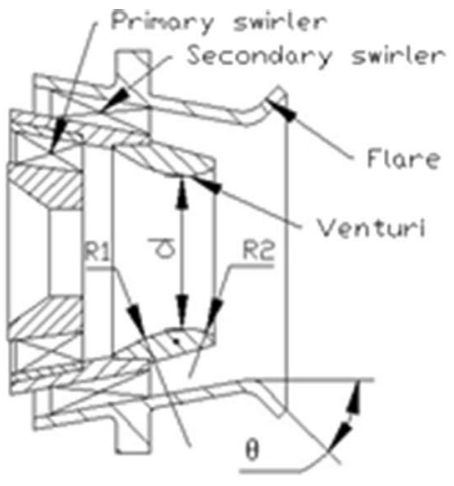

a

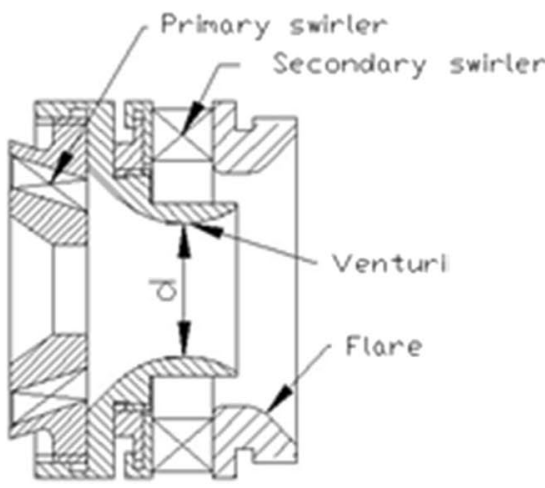

b

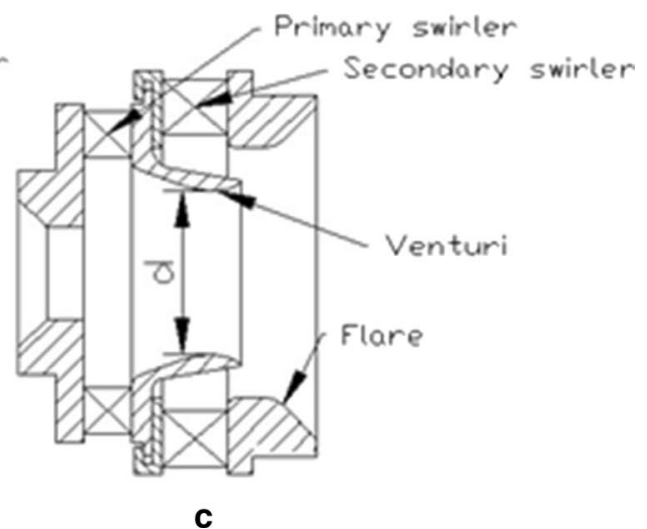

c

Fig. 3 Schematic of swirl cups (a dual-axial swirl cup, b axial-radial swirl cup, c dual-radial swirl cup)

swirl cups. As showed in Fig. 1, it consists of a pressureswirl atomizer, swirl cup, primary holes and dilution holes. The height of the combustor dome is $92 \mathrm{~mm}$. The length between the dome and the combustion liner exit is $226 \mathrm{~mm}$. The combustor reference velocity is about $20 \mathrm{~m} / \mathrm{s}$ under the design condition, and the residence time of air flow in combustor is about $0.025 \mathrm{~s}$. The combustor used in this study was designed and fabricated to provide visualization and photography capabilities through a window located at the flank of the combustor. A pressure-swirl atomizer combined with swirl-cup is employed to sustain good atomization. The picture of the test rig and swirl cups employed in the experiment are showed in Fig. 2.

Three types of swirler cups are employed in the experiment and the schematics are showed in Fig. 3. As showed in Fig. 3, the swirl cup is consisting of primary swirler, secondary swirler, venturi and flare. The combination of primary swirler and secondary swirler is varied by using axial swirler and radial swirler. The primary swirler is applied to introduce high-velocity air, thus promote atomization. The purpose of secondary swirler is the presence of a vortex breaking bubble [19], thus resulting in the formation recirculation zones. The venturi and flare are assembled to promote fuel air mixing and avoid flash back. The different flow splits were obtained by the variation of swirl cup geometry. The primary holes arrangement was also varied to obtain different flow splits. The experimental conditions for geometric parameters of combustors are shown in Table 1.

The usual operating procedures of LBO experiment are as follows. At the beginning, the pressure and air flow rate are maintained at low level. After the ignition, the flow rate of air and fuel are increased simultaneously until the pressure of combustor rise to $220 \mathrm{kPa}$ which refers to the idle condition. As the thermal equilibrium of system attains is reached, the fuel flow rate is decreased slowly until flame blowout happens. The LBO limits were recorded as the ratio of fuel and total airflow. The airflow rate in the experiment is about $0.6 \mathrm{~kg} / \mathrm{s}$ and the inlet temperature is $298 \mathrm{~K}$. Liquid fuel Jet A-1 and gaseous fuel methane were employed in the experiment under the same operating conditions. The flow rate of Jet A-1 and methane were measured by a turbine flow meter and a mass flow meter, respectively. The airflow rate was measured by a vortex flow meter. The gaseous methane was pumped from a high pressure tank and delivered to the fuel injector, while the Jet A-1 was pumped with oil pressure of 30 bars by an oil-pressure pump. Experiment for each fuel was repeated 
Table 1 Geometry parameters of combustors

\begin{tabular}{|c|c|c|c|c|c|c|c|c|}
\hline \multirow[t]{2}{*}{ Configuration } & \multicolumn{3}{|l|}{ Swirl cup } & \multicolumn{3}{|c|}{ Venturi } & \multirow{2}{*}{$\begin{array}{l}\text { Flare } \\
\theta\end{array}$} & \multirow{2}{*}{$\begin{array}{l}\text { Primary hole } \\
\mathrm{A}_{3}\end{array}$} \\
\hline & Type & $\mathrm{A}_{1}$ & $\mathrm{~A}_{2}$ & $\mathrm{R}_{1}$ & $\mathrm{R}_{2}$ & d & & \\
\hline 1 & Dual-axial & 147.5 & 186.6 & 6.3 & 6.3 & 18 & 45 & 102 \\
\hline 2 & & 178.8 & 186.6 & & & & & \\
\hline 3 & & 111.4 & 186.6 & & & & & \\
\hline 4 & & 147.5 & 223 & & & & & \\
\hline 5 & & 147.5 & 150.4 & & & & & \\
\hline 6 & & & & & & 16 & & \\
\hline 7 & & 147.5 & 186.6 & 14 & 4 & 18 & & 84 \\
\hline 8 & & & & & & & 35 & 102 \\
\hline 9 & Axial-radial & 73.35 & 190.7 & 6.3 & 6.3 & & 45 & 84 \\
\hline 10 & & 73.35 & 190.7 & 14 & 4 & & & 102 \\
\hline 11 & Dual-radial & 144 & 190.7 & 6.3 & 6.3 & 13 & & \\
\hline 12 & & 72 & 190.7 & & & & & \\
\hline 13 & & 72 & 95.3 & & & & & \\
\hline 14 & & 72 & 95.3 & & & & & 84 \\
\hline 15 & & 144 & 95.3 & & & & & \\
\hline
\end{tabular}

thrice for the repeatability, and the measurement uncertainty of lean blowout limits were within $\pm 4 \%$.

Direct optical access to the combustor for visualization is provided by a side-wall with a piece of quartz glass installed in it. The flame shape close to LBO was recorded by an optics camera through the visualization window showed in Fig. 1. And the flame volume is approximately determined by rotating the flame contour (in optical image) along the centerline. The flow splits and flow dynamics of swirl cup were obtained from the simulated cold flow field by commercial software Fluent. RANS is applied in the numerical simulation as the solution of turbulence because of the low expense and main concerns in average flow.

\section{Results and discussion}

\subsection{Blowout limits of liquid fuel}

Testing with the liquid fuel Jet A-1 has been completed for fifteen values of swirl cup airflow. Without combustion, the required airflow rate and swirl cup splits were established. Once the thermal stability was established, the flow splits and flow rates were taken again. The flow splits of the swirl cups were obtained from the cold flow field. However, the relative flow split of swirl cup would be similar for cold flow and reaction flow because the combustion occurred downstream of swirl cup.

Figure 4 shows the relationship between LBO limits and primary swirler airflow for dual-axial swirl cup. As shown in Fig. 4, the LBO limits decrease with the primary swirler airflow. The primary swirler is employed to promote

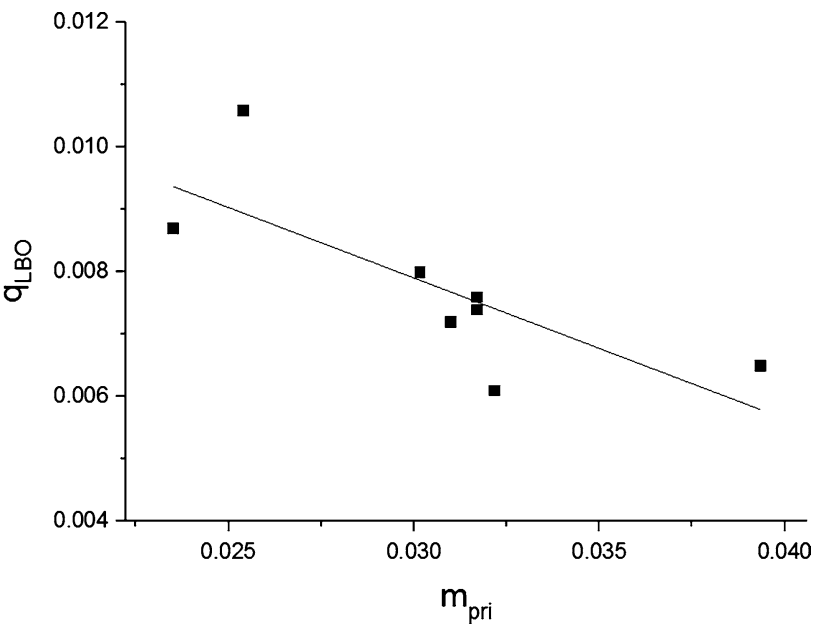

Fig. 4 Relationship of LBO limits and primary swirler airflow for dual-axial swirl cups

atomization. The increase airflow of primary swirl would result in good atomization, thus increase the concentration of liquid fuel vapor. On the other hand, the increase of airflow would lower the local fuel air ratio (FAR), thus lead to the occurrence of flame lean blowout. The increase of primary swirler airflow would also cause the variation of velocity profile at jet exit and eventually affect the flow dynamics of burning zone [8]. Thus, both atomization and swirl cup flow dynamics would affect LBO limits. However, the dominant factor cannot be observed in Fig. 4, and more analysis would be presented in following discussions.

Figure 5 shows the decrease of LBO limits with the secondary swirler airflow for dual-axial swirl cup. The 


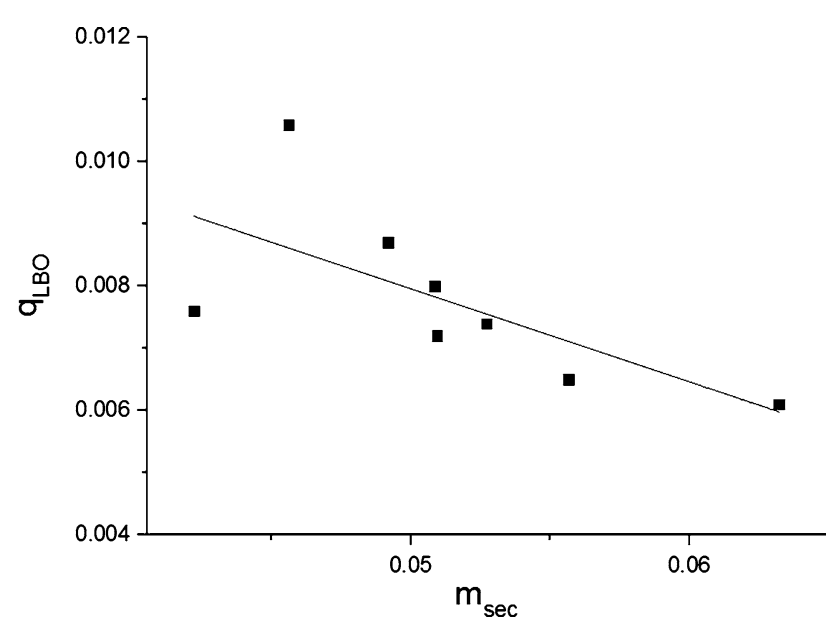

Fig. 5 Relationship of LBO limits and secondary swirler airflow for dual-axial swirl cups

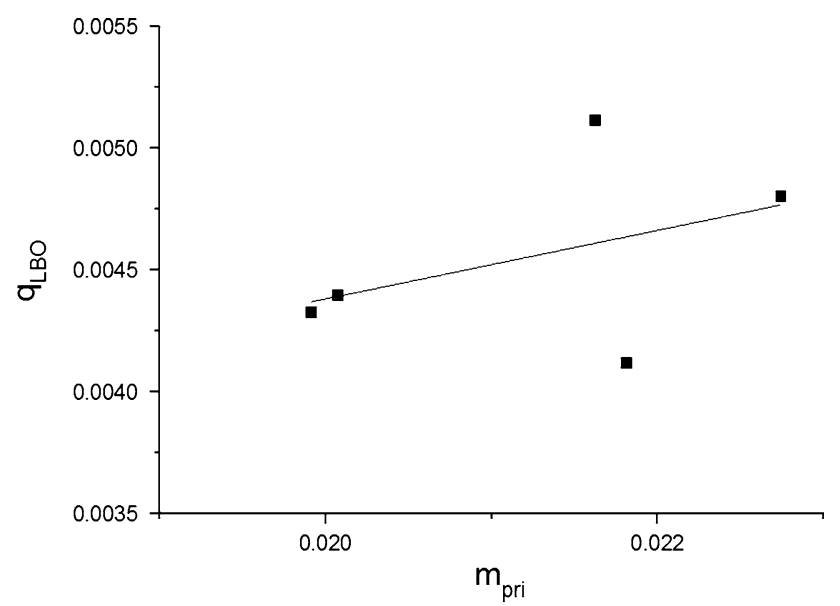

Fig. 6 Relationship of LBO limits and primary swirler airflow for dual-radial swirl cups

airflow of secondary swirler is more than primary airflow because high velocity is required to produce the recirculation zone. The airflow of secondary swirler would affect the swirl intensity and the length of recirculation zone, thus result in the variation of burning zone airflow. Based on the experimental results obtained by Sturgess [8], the LBO limits would increase with burning zone airflow. However, the increase airflow of secondary swirler would also cause the decrease of FAR near the fuel injector. According to M. Stohr [20], the flame root located above the fuel injector is significant for the flame stability. The decrease of FAR near the fuel injector would lead to the failure of sustainment of flame root, thus result in the flame lean blowout.

Figure 6 shows the relationship of primary swirler airflow and LBO limits for dual-radial swirl cup. As shown in Fig. 6, the LBO limits increase with the primary swirler

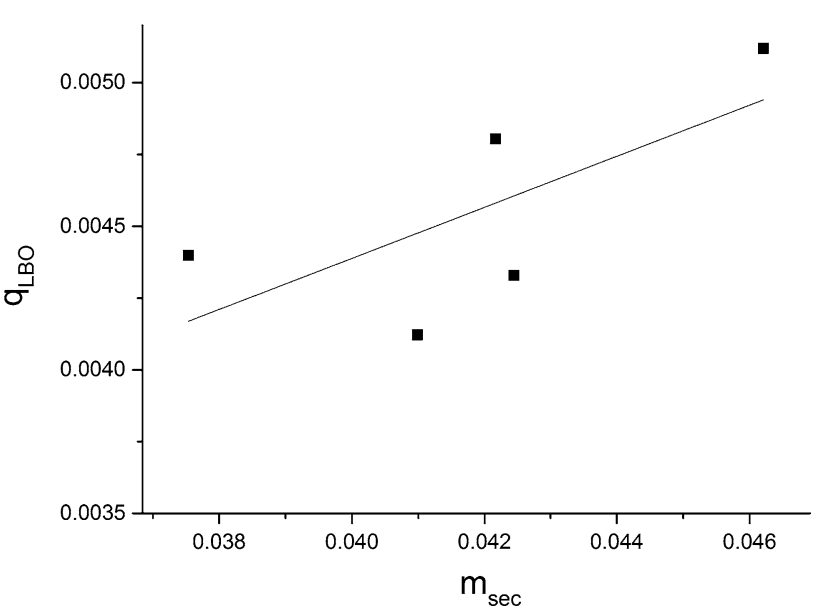

Fig. 7 Relationship of LBO limits and secondary swirler airflow for dual-radial swirl cups

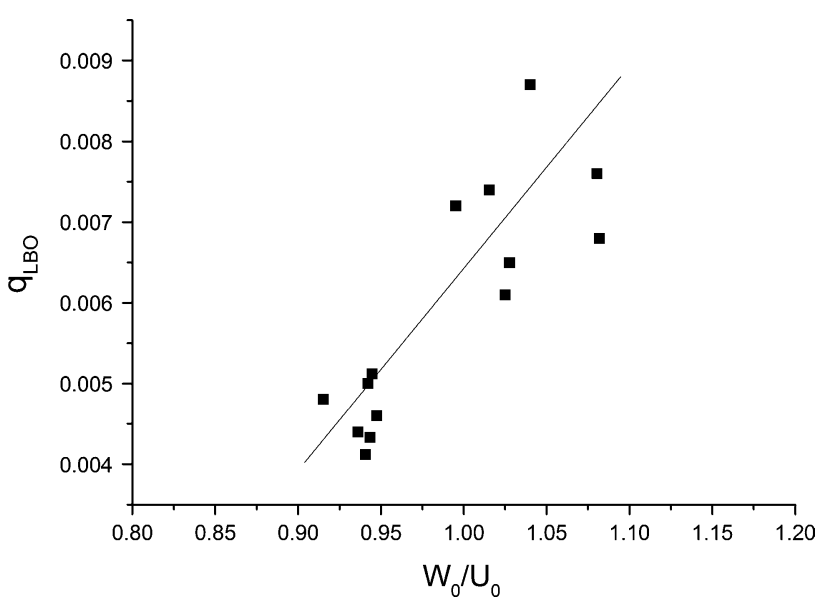

Fig. 8 Relationship of LBO limits and ratio of $\left(\mathrm{W}_{0} / \mathrm{U}_{0}\right)$ for three swirl cups with using Jet A-1

airflow. Figure 7 also shows the relationship between LBO limits and secondary swirler airflow for dual-radial swirl cup. As shown in Fig. 7, the LBO limits increase with the secondary swirler airflow. It is observed that the trend of LBO limits for dual-radial swirl cup is opposite to the trend for dual-axial swirl cup. The main different effects on LBO limits between dual-axial swirl cup and dualradial swirl cup are flow dynamics and atomization. With the increase of airflow, the atomization would be promoted for both dual-axial and dual-radial swirl cups, thus smaller fuel droplets would be obtained. However, the fuel vapor concentration near the fuel injector cannot be determined because the amount of evaporation and airflow increase simultaneously. On the other hand, the swirl cup flow dynamics would also be different with the increase of airflow for dual-axial and dual-radial swirl cups. Therefore, the reason for the different trend of LBO limits for 
dual-axial swirl cup and dual-radial swirl cup is required for more evidences to be confirmed.

Figure 8 shows the relationship between the LBO limits and ratio of $\left(\mathrm{W}_{0} / \mathrm{U}_{0}\right) . \mathrm{W}_{0}$ and $\mathrm{U}_{0}$ is the mean tangential velocity and mean axial at swirl cup exit. The ratio of $\left(\mathrm{W}_{0} /\right.$ $\mathrm{U}_{0}$ ) reflects the swirl intensity of the swirl cup. As shown in Fig. 8, the LBO limits increase with the ratio of $\left(\mathrm{W}_{0} / \mathrm{U}_{0}\right)$ for all of three swirl cups. Jeng [21] has studied the correlation of $\mathrm{W}_{0} / \mathrm{U}_{0}$ and swirl number $\mathrm{S}$, and the equation for swirl number can be written as:

$S=0.75 \frac{W_{0}}{U_{0}}$

The swirl intensity is characterized by the swirl number $\mathrm{S}$, the ratio of the axial flux of angular momentum to the axial flux of axial momentum, as originally proposed by Beér and Chigier [22]:

$S=\frac{\int_{0}^{R} U W \mathrm{r}^{2} d r}{R \int_{0}^{R} U^{2} r d r}$

With the increase of swirl intensity, the combustion air form primary holes would increase because the recirculation zone turns to be large. Therefore, the FAR of burning zone would decrease, and the temperature of burning zone would also decrease, as a result of the entrainment of large amount of cool air from primary holes into burning zone. Based on the experimental results of Sturgess [8], the LBO limits increase with the burning zone FAR for a practical combustor with primary holes. Thus, the increase of swirl intensity would cause the increase of LBO limits. On the other hand, the recirculated airflow from primary holes is cool air instead of high temperature combustion products, thus, the flame root would not be sustained at low temperature and eventually flame lean blowout occurs. For both dual-axial swirl cups and dual-radial swirl cups, the LBO limits increase with the swirl intensity. Hence, it is reasonable to make a conclusion that the variation of swirl cup airflow would result in the change of swirl intensity, which is a dominant factor to affect LBO limits. However, the effect of atomization on LBO limits cannot be ignored based on the analysis of liquid fuel. The effect of atomization will be separated in the gas fuel experiment and related analysis would be presented in the following section.

\subsection{Blowout limits of gaseous methane}

Experiment for different configurations were conducted to investigate the effects of fuel atomization on LBO limits by using liquid fuel (Jet A-1) and gaseous fuel (methane). Figure 9 is the comparisons of LBO limits between Jet A-1 and methane for dual-axial swirl cups under the same inlet pressure. As shown in Fig. 9. The LBO limits of Jet A-1 are

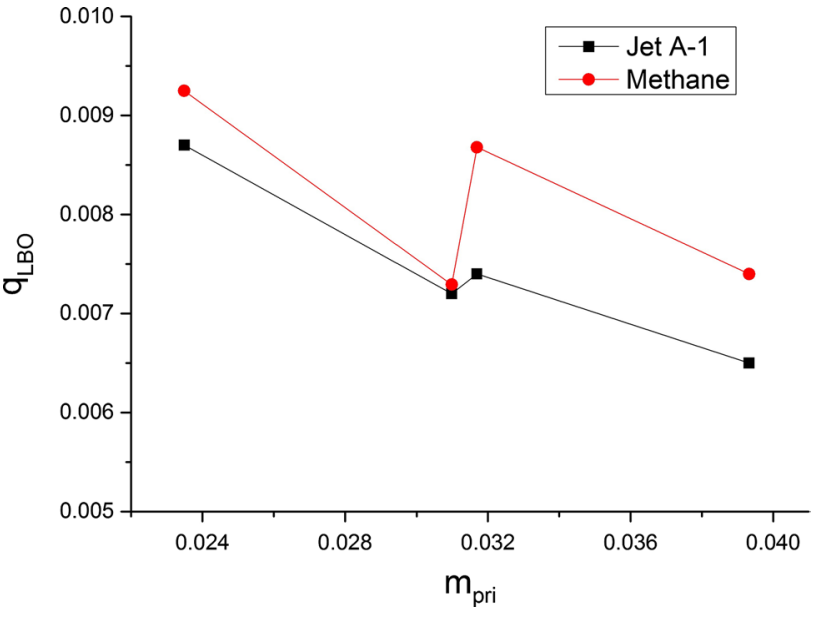

Fig. 9 Relationship of LBO limits and primary swirler airflow for dual-axial swirl cups with Jet A-1 and methane

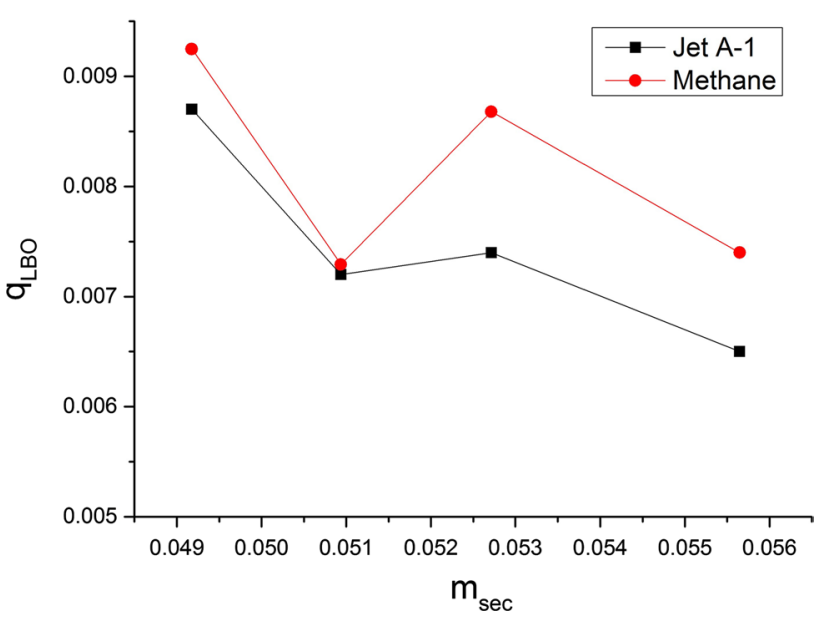

Fig. 10 Relationship of LBO limits and secondary swirler airflow for dual-axial swirl cups with Jet A-1 and methane

higher than LBO limits of methane. It is also observed that the relationship of LBO limits and primary swirler airflow is similar between Jet A-1 and methane. The LBO limits decrease with primary swirler airflow for both Jet A-1 and methane. Figure 10 also showed the LBO limits of Jet A-1 and methane for secondary swirler of dual-axial swirl cups, and similar trend of LBO limits with secondary swirler airflow are observed for Jet A-1 and methane.

Without evaporation, the quick-mixing of gas fuel and air would be realized, thus the local equivalence ratio near the combustor dome would not be rich because the quickmixing. However, the local rich-fuel zone near the combustor dome would be obtained for liquid fuel because of the evaporation before combustion. The rich fuel zone near the combustor dome would results in local hot spots with high 


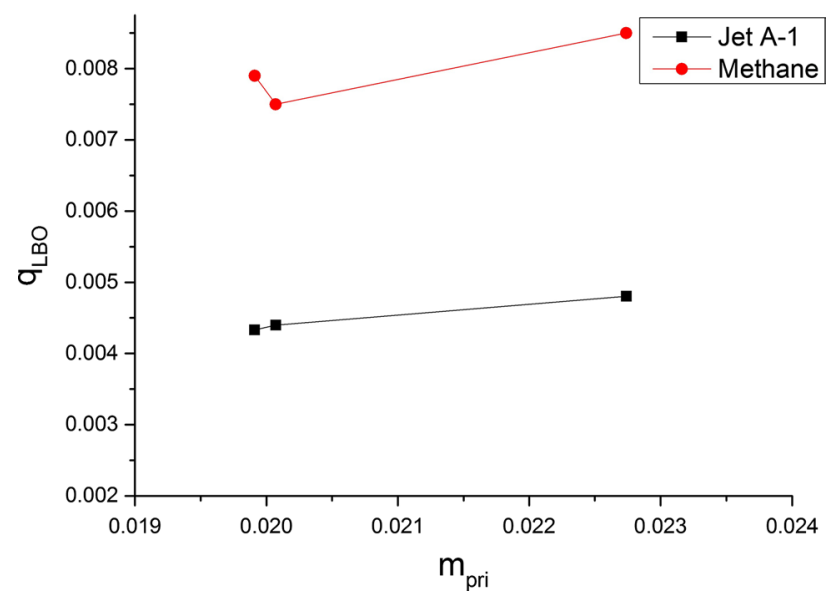

Fig. 11 Relationship between LBO limits and airflow of primary swirler for dual-radial swirl cups with Jet A-1 and methane

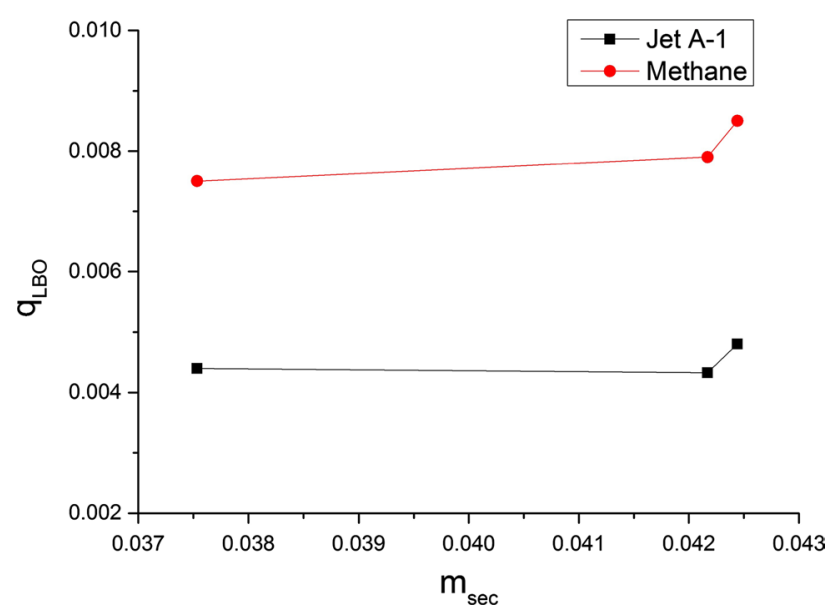

Fig. 12 Relationship between LBO limits and airflow of secondary swirler for dual-radial swirl cups with Jet A-1 and methane

temperature, thus sustaining the flame stability. Therefore, the LBO limits of methane is higher than Jet A-1. For dualaxial swirl cups, the LBO limits decrease with the airflow of primary and secondary swirlers with using both liquid fuel and gas fuel. Hence, the effect of atomization is insignificant on LBO limits with the variation of dual-axial swirl cup airflow.

Figures 11 and 12 showed the relationship of LBO limits and swirler airflow for dual-radial swirl cup with using Jet A-1 and methane. As showed in Figs. 11 and 12, the tendency of LBO limits with swirler airflow is similar for methane and Jet A-1. Therefore, for both dual-axial swirl cups and dual-radial swirl cups, the relationship of LBO limits and swirl cup airflow is similar between Jet A-1 and methane. Hence, it is appropriate to conclude that the atomization is insignificant for the LBO limits with the variation of swirl cup airflow. The atomizer employed in the

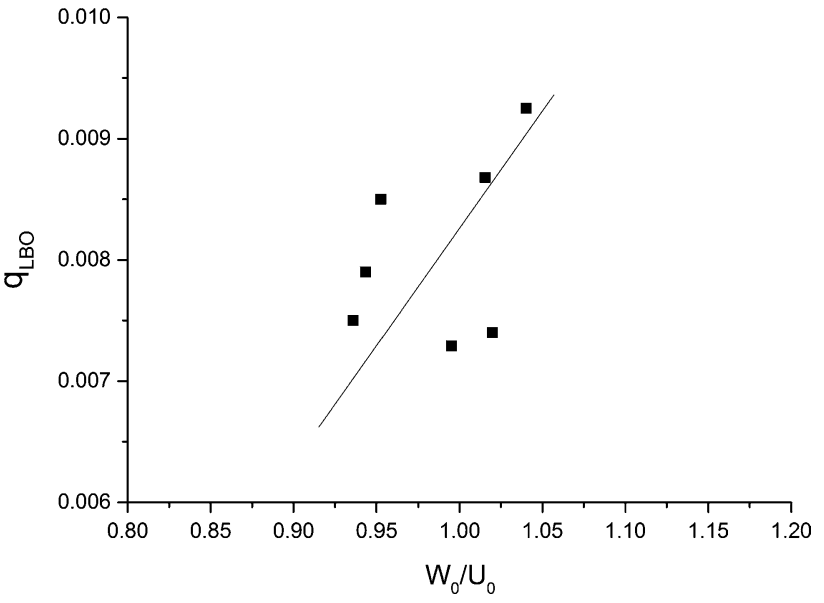

Fig. 13 Relationship between LBO limits and ratio of $\left(\mathrm{W}_{0} / \mathrm{U}_{0}\right)$ with using methane

experiment is pressure-swirl atomizer, and its atomization quality is good because of high delivery pressure under the idle condition. Meanwhile, the inlet pressure of combustor under the idle condition is $220 \mathrm{kPa}$ which is sufficient for generation of high-velocity air stream to promote the breakup of fuel droplets. Hence, the system would be fully prevaporized, as a consequence, the effect of atomization on LBO limits would be negligible when changing the flow splits of swirl cup.

Figure 13 showed the relationship of LBO limits and the ratio of $\left(\mathrm{W}_{0} / \mathrm{U}_{0}\right)$ with using gas fuel methane. As shown in Fig. 13, the LBO limits increase with the ratio of $\left(\mathrm{W}_{0} /\right.$ $\mathrm{U}_{0}$ ). Hence, the LBO limits increase with swirl intensity for both Jet A-1 and methane. It would be appropriate to make a conclusion that the swirl intensity is a dominant factor to affect LBO limits with the variation of swirl cup airflow. However, the effect of atomization on LBO limits would be insignificant under the idle condition because of the system would be fully prevaporized.

\subsection{Prediction of liquid fuel LBO limits}

An improved semi-empirical LBO correlation was obtained by Huang [16] in previous works for practical gas turbine combustors. The correlation for the prediction on LBO limits can be written as follow,

$q_{L B O}=\frac{43}{V_{c}}\left(\frac{\alpha}{\sqrt{\beta}}+(1-\alpha) \sqrt{\beta}\right)^{2}\left(\frac{m_{a}}{P_{3}^{1.3} \exp \left(T_{3} / 300\right)}\right)\left(\frac{D_{0}^{2}}{\lambda_{\text {eff }} L C V}\right)$

where $\alpha$ is the combustor dome airflow fraction, $\beta$ is the non-dimensionless flame volume. The first bracket in Eq. (3) represents the effect of combustor geometry on LBO limits, and the second bracket and third bracket 


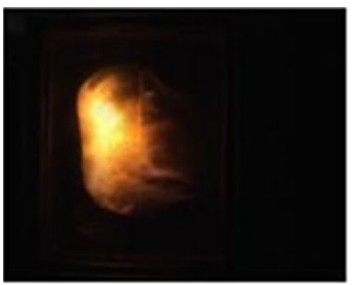

$\phi_{\text {Dome }}=0.478$

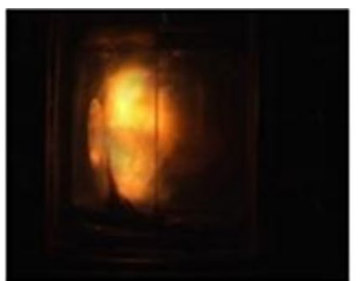

$\phi_{\text {Dome }}=0.485$

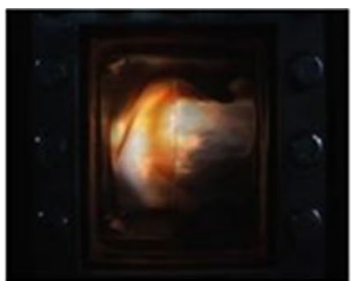

$\phi_{\text {Dome }}=0.502$

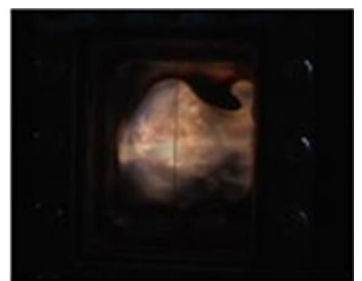

$\phi_{\text {Dome }}=0.543$

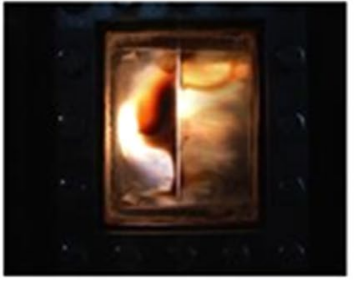

$\phi_{\text {Dome }}=0.559$

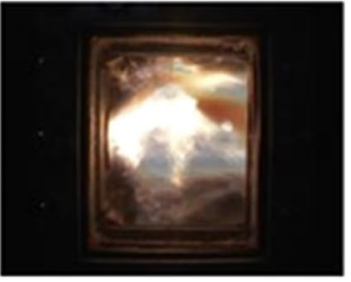

$\phi_{\text {Dome }}=0.692$

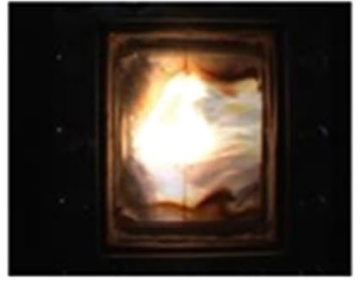

$\phi_{\text {Dome }}=0.82$

Fig. 14 Photographs illustrating the flame structure with using Jet A-1 near the flame blowout for different swirl cup configurations

represent the effects of operating conditions and atomization, respectively. However, there are two issues in Eq. (3) for the applications in general combustors. Firstly, the effect of swirl intensity on LBO limits is not included in the correlation. As discussed above, the swirl intensity poses a significant role on LBO limits. Secondly, the flame volume value $\beta$ is obtained from experimental results, thus, it would be a unknown quantity in design stage for a general combustor. To apply the Eq. (3), it is necessary to make improvements of Eq. (3) to meet the design requirements.

Figure 14 shows the flame structures of combustors with different swirl cups near the flame blowout. As shown in Fig. 14, the flame length increases with dome equivalence ratio $\phi_{\text {Dome }}$, which defined as,

$\phi_{\text {Dome }}=\left(\frac{m_{f}}{m_{\text {Dome }}}\right) / \zeta$

where $\mathrm{m}_{\mathrm{f}}$ is the fuel flow, $\mathrm{m}_{\text {Dome }}$ is the combustor dome airflow, and $\zeta$ is the stoichiometric ratio. Combustor dome airflow includes swirl cup airflows and dome cooling airflows. With the increase of $\phi_{\text {Dome }}$, the primary zone equivalence ratio can exceed unity. Under these circumstances, the flame would propagate primary zone and the flame length would be greater than primary zone in length. Therefore, the flame volume would be related to the dome equivalence ratio.

As reported in literatures [7, 23], the flame length is also governed by swirl intensity for swirl combustors. However, the relationship of swirl intensity and flame length has not been understood clearly. Figure 15 shows the correlation of flame volume $\beta$ and combustor geometry parameter

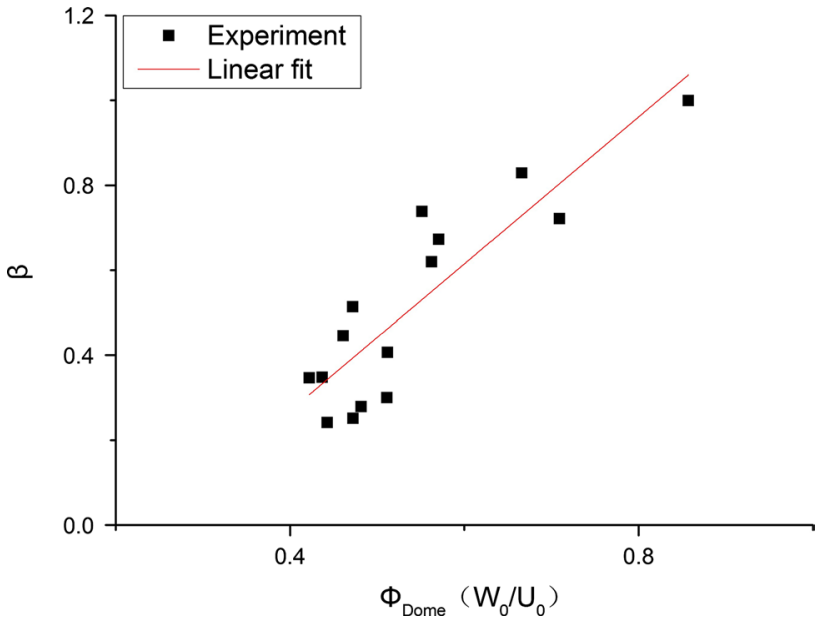

Fig. 15 Correlation of flame volume $\beta$ and $\left(\mathrm{W}_{0} / \mathrm{U}_{0}\right) \phi_{\text {Dome }}$

$\phi_{\text {Dome }}\left(\mathrm{W}_{0} / \mathrm{U}_{0}\right)$, and an empirical correlation for flame volume was obtained as follow,

$\beta=\phi_{\text {Dome }}\left(W_{0} / U_{0}\right)$

The LBO limits can be written as

$\mathrm{q}_{L B O}=\frac{\alpha \phi_{\text {Dome }}}{\zeta}$

Thus, the flame volume can be expressed as

$\beta=\frac{\zeta \mathrm{q}_{L B O}}{\alpha}\left(W_{0} / U_{0}\right)$

Hence, substitute Eq. (7) into Eq. (3) will give 


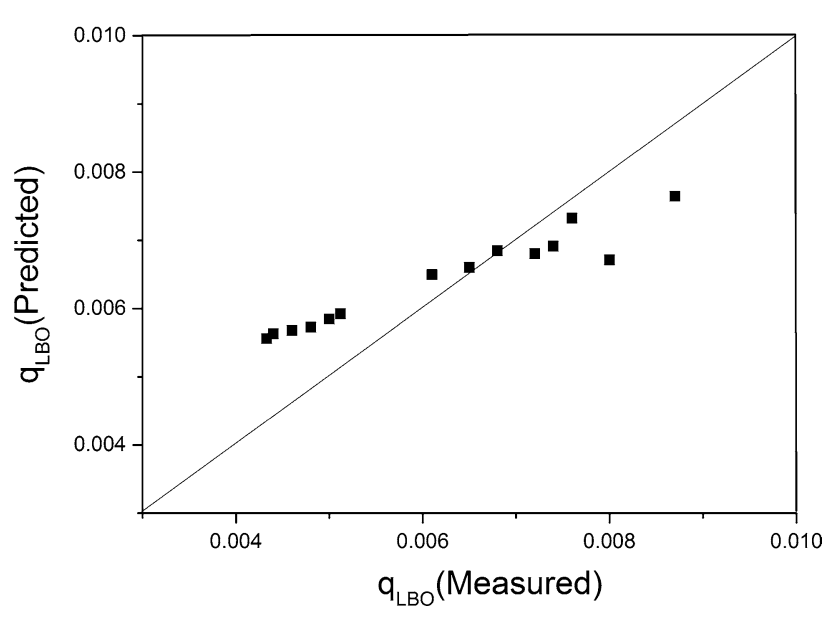

Fig. 16 Comparisons of measured LBO limits and predicted LBO limits

$$
\begin{aligned}
q_{L B O}= & \frac{43}{V_{c}}\left(\alpha+1.5 \sqrt{\frac{1}{\zeta q_{L B O}\left(W_{0} / U_{0}\right)}}\right. \\
& \left.+(1-\alpha) \sqrt{\frac{\zeta q_{L B O}\left(W_{0} / U_{0}\right)}{\alpha}}\right)^{2} \\
& \left(\frac{m_{a}}{P_{3}^{1.3} \exp \left(T_{3} / 300\right)}\right)\left(\frac{D_{0}^{2}}{\lambda_{\text {eff }} L C V}\right)
\end{aligned}
$$

The LBO limits can be obtained with the solution of Eq. (8). Figure 16 shows the comparisons of measured LBO limits and predicted LBO limits, and the uncertainty is within $\pm 20 \%$. In general, the effect of swirl intensity was introduced to the LBO prediction model, and the blowout data was successfully correlated with the predicted values. However, the effect of swirl intensity was correlated with flame volume by a simple phenomeno-logical correlation, and a universal correlation did not result. The heterogeneous combustion in practical combustors is complicated, thus, it is essential to develop successful modeling techniques for lean blowout.

\section{Conclusions}

1. Experimental LBO data have been provided for practical combustors with different flow splits under idle condition. Both liquid fuel and gas fuel were employed in the experiment to investigate the effect of flow dynamics and atomization on LBO limits.

2. With using both Jet A-1 and methane under idle condition, the LBO limits decrease with the airflow of primary and secondary swirlers for dual-axial swirl cup, and increase with the airflow of primary and secondary swirlers for dual-radial swirl cup.
3. The swirl intensity is a dominant factor to affect the LBO limits when varying the swirl cup flow splits. For both Jet A-1 and methane, the LBO limits increase with the swirl intensity. The system would be fully prevaporized, thus the performance of atomization is almost unchanged, as a result the effect of atomization on LBO limits is not a significant factor.

4. The flame volume increases with the dome equivalence ratio, and an empirical correlation of flame volume was obtained. The effect of swirl intensity is modeled in the LBO prediction model by phenomeno-logical correlations.

5. Fifteen combustors with different flow splits were employed to verify the accuracy of LBO prediction model. The uncertainty of the method to predict LBO limits is within $\pm 20 \%$. The experimental data were correlated successfully with a universal LBO prediction model developed in previous works. However, more theoretical analysis need to be conducted for modeling the relationship of flame volume and swirl intensity.

Open Access This article is distributed under the terms of the Creative Commons Attribution 4.0 International License (http://creativecommons.org/licenses/by/4.0/), which permits unrestricted use, distribution, and reproduction in any medium, provided you give appropriate credit to the original author(s) and the source, provide a link to the Creative Commons license, and indicate if changes were made.

\section{References}

1. Correa SM (1993) A review of NOx formation under gas-turbine combustion conditions. Combust Sci Technol 87(1-6):329-362

2. Anderson DN (1981) Ultra-lean combustion at high inlet temperatures. NASA STI/Recon Tech Rep N 81:14398

3. Imamura A, Yoshida M, Kawano M et al (2001) Research and development of a LPP combustor with swirling flow for low NOx[C]//37th Joint Propulsion Conference and Exhibit, AIAA-2001-3311

4. Giridharan MG, Mongia HC, Jeng SM (2003) Swirl cup modeling part VIII: spray combustion in CFM56 single cup flame tube. AIAA Pap 2003:319

5. Lefebvre AH (1983) Gas turbine combustion, 1st edn. McGrawHill Book Company, New York

6. Ateshkadi A, McDonell VG, Samuelsen GS (1998) Effect of hardware geometry on gas and drop behavior in a radial mixer spray $[\mathrm{C}] / /$ Symposium (International) on Combustion. Elsevier, 27(2): 1985-1992

7. Durbin MD, Ballal DR (1996) Studies of lean blowout in a step swirl combustor. J Eng Gas Turbines Power 118(1):72-77

8. Sturgess GJ, Shouse D (1997) Lean blowout research in a generic gas turbine combustor with high optical access. J Eng Gas Turbines Power 119(1):108-118

9. Lefebvre AH (1985) Fuel effects on gas turbine combustionignition, stability, and combustion efficiency. J Eng Gas Turbines Power 107(1):24-37

10. Plee SL, Mellor AM (1979) Characteristic time correlation for lean blowoff of bluff-body-stabilized flames. Combust Flame 35:61-80 
11. Ozawa RI (1971) Survey of basic data on flame stabilization and propagation for high speed combustion systems. The Marquart Co., TR AFAPL-TR-70-81

12. Driscoll JF, Rasmussen CC (2005) Correlation and analysis of blowout limits of flames in high-speed airflows. J Propul Power 21(6):1035-1044

13. Hoffmann S, Habisreuther P, Lenze B (1994) Development and assessment of correlations for predicting stability limits of swirling flames. Chem Eng Process 33(5):393-400

14. Mongia HC, Vermeersch M, Thomsen D et al (2001) A simple reactor-based approach for correlating lean blowout of turbo propulsion engine combustors. AIAA Pap 2001:3420

15. Ateshkadi A, McDonell VG, Samuelsen GS (2000) Lean blowout model for a spray-fired swirl-stabilized combustor. Proc Combust Inst 28(1):1281-1288

16. Xie F, Huang Y, Hu B et al (2012) Improved semiempirical correlation to predict lean blowout limits for gas turbine combustors. J Propul Power 28(1):197-203

17. Hu B, Huang Y, Wang F (2013) FIA method for LBO limit predictions of aero-engine combustors based on FV model. Aerosp Sci Technol 28(1):435-446
18. Xie F, Huang Y, Wang F et al (2010) Visualization of the lean blowout process in a model combustor with a swirl cup[R]. ASME-GT-2010-22534

19. Patel N, Kırtaş M, Sankaran V et al (2007) Simulation of spray combustion in a lean-direct injection combustor. Proc Combust Inst 31(2):2327-2334

20. Stöhr M, Boxx I, Carter C et al (2011) Dynamics of lean blowout of a swirl-stabilized flame in a gas turbine model combustor. Proc Combust Inst 33(2):2953-2960

21. Sheen HJ, Chen WJ, Jeng SY (1996) Recirculation zones of unconfined and confined annular swirling jets. AIAA J 34(3):572-579

22. Beér JM, Chigier NA (1972) Combustion aerodynamics. Krieger Publishing Company, New York, p 156

23. Durbin MD, Vangsness MD, Ballal DR, Katta VR (1996) Study of flame stability in a step swirl combustor. ASME J Eng Gas Turbines Power 118(2):308-315 